\title{
Research on Manufacture and Test of Advanced Composite Material Flange
}

\author{
Guoquan Tao*, ZhenGuo Liu, Ming Yun Lv and SiSi Chen
}

School of Aeronautical Science and Engineering, Beihang University, Beijing 100191, China

\begin{abstract}
Due to the problems of potential corrosion and thermal expansion differences between traditional metal connecting pieces and carbon fiber poles, it is difficult for them to meet the operating requirements of truss structures in the environment of stratosphere. Based on the large scale composite space truss structure of stratosphere aerostats, the carbon fiber flange connection joints were studied in the present paper. Adopting the three-dimensional full fivedirectional braiding technology, Toray T700S $-12 \mathrm{~K}$ carbon fiber is used as the raw material to manufacture flange joint preform, and to manufacture flange forming by RTM(resin transfer molding) process. As demonstrated by tensile and bending tests, the composite flange joints have better mechanical properties than flanges manufactured by aviation aluminum alloy, and meet requirements of stratosphere truss structure connecting pieces. In conjunction with the results of finite element analysis, mechanical properties can be further enhanced by the improvements of the braiding process, the forming process and the physical dimension.
\end{abstract}

Keywords: Advanced composite material flange, manufacture, test, finite element analysis.

\section{INTRODUCTION}

Three-dimensional braided composite material, a new type of composite material, is a combined product of the three-dimensional braiding technology and the advanced composite material technology. It is essentially developed and applied in high and new technology fields represented by the aerospace technology. As the fiber bundles extend along a plurality of spatial directions and cross with each other, the integrity of the composition is good and the drawbacks of low intensity and easy lamination between layers of the laminated composite material are overcame [16]. Meanwhile, the high specific strength, the high specific stiffness, and the very strong designability of the threedimensional braided composite material play an essential role in the weight reducing of aerospace structures.

Aerostats have become the public research hotspot. One of the key technologies is the research of large scale truss structure which is light in weight and high in strength. The large scale truss structure in spacecraft is usually composed of carbon fiber poles and metal joints. Through the improvements of the connection between the carbon fiber poles, the weight of the truss structures is further reduced, the bearing efficiency of the structure is improved, and problems of the potential corrosion and the thermal expansion rate between the aluminum alloy and carbon fiber are solved.

In the present paper, the carbon fiber flange preform is manufactured by the four steps three-dimensional braiding technology, and the three-dimensional braided flange specimen is developed in combination with the RTM process. Also, advanced composite material flange is used to subs-

*Address correspondence to this author at the School of Aeronautical Science and Engineering, Beihang University, Beijing 100191, China; Tel: +86-10-82329492-101 (Office), +86-13810018312 (Mobile); Fax: +86-1082315584; E-mail: ac97531@163.com titute the aviation aluminum alloy joint of carbon fiber truss structure. As tested by tensile and bending tests, under the condition of same quality, the tensile and bending property of the former is better than latter, so that the expected result is reached. The whole manufacturing process is divided into five steps: manufacture of three-dimensional braided preform, manufacture of the RTM process mold, injection, curing and release of the resin.

\section{THE PROCESSING OF THE THREE-DIMEN- SIONAL BRAIDED PREFORM}

One of the characteristics of three-dimensional braiding is that different shapes of heterotype whole pieces can be directly braided. As for the reasons, in one aspect, the size of the cell cube of the basic structure of three-dimensional braidings can be changed with the changes of the shape and size dimension of the preforms. In another aspect, braiding process is varied, and processing parameters can be changed to adjust the process to meet the requirements of the shape of the preforms, thereby to achieve whole braiding.

In the present paper, the four steps three-dimensional braiding process is used to manufacture the flange preform. Many structures with different cross-sectional shapes can be braided by the four steps, for example, tabular, tubular, semicylinder, and cylinder. The four steps braiding method is introduced as follows, taking tabular structure as example. A square machine is used to braid the tabular structure. The theory of the four steps process of the 6 lines 4 rows structure is described in Fig. (1). In the first step, all the bobbins in row move horizontally, in which, adjacent rows move in reverse directions, as shown by the arrows in Fig. (1b). In the second step, all the bobbins in column move vertically, in which, adjacent rows move in reverse directions, as shown by the arrows in Fig. (1c). The third step is similar with the first step, except that the rows move 
reversely, that is to say, all the rows return to the state of the first step (Fig. 1d). In the fourth step, all the columns return to the state of the second step, only the position of respective bobbin is changed (Fig. 1e). Thus, one braiding cycle is completed and the braider returns to the initial state of the circle again, only that the position of respective bobbin is changed (Fig. 1a). These four steps are repeated afterwards, and the four steps braiding is achieved.

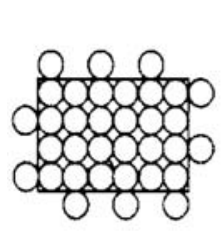

(a)

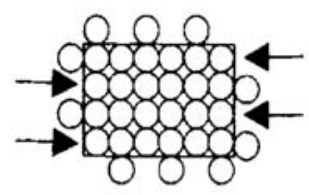

(b)

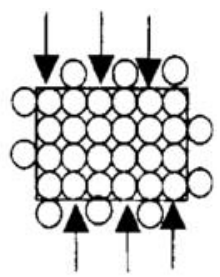

(c)

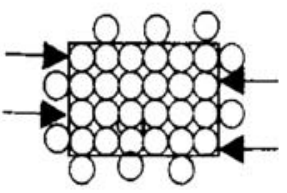

(d)

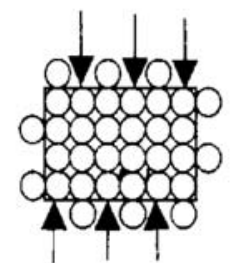

(e)
Fig. (1). The theory of four steps tabular braiding process of threedimensional braiding.

The braider used for tubular braiding is a round machine. The round machine is actually a square machine and the rows of which are connected between the beginning and the end. The process of a four steps tubular braiding is similar to the tabular braiding, only that the horizontal movement is changed to the tangential movement and the vertical movement is changed to radial movement.

The fabric construction is divided into many types including three-dimensional four directions, three-dimensional five directions, three-dimensional full five-directions, threedimensional six directions or even three-dimensional seven directions. In the structure of three-dimensional four directions, there is no axial direction yarn passing through the pitch of the braiding. In the structure of three-dimensional

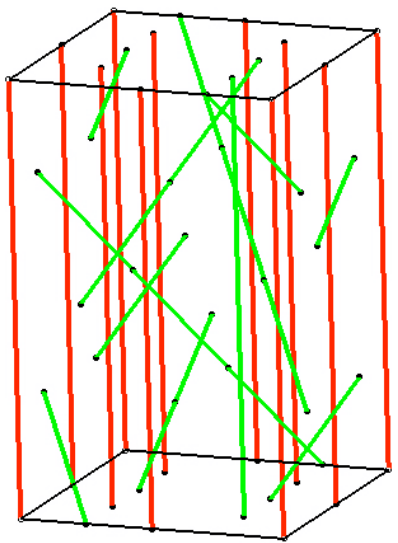

Fig. (2). Schematic illustration of the fiber structure of the threedimensional braiding. five directions, there is one axial direction yarn passing through the pitch every other pitch length. Whereas in the structure of three-dimensional full five-directions, there are axial direction yarns passing through all pitches, and the thickness of which is far larger than the structure of threedimensional four directions or three-dimensional five directions. The present flange which has the structure of threedimensional full five-directions [7] is shown as Fig. (2).

T700S-12K carbon fiber from Toray Co., Japan is chosen as the braiding material, its basic characteristics are listed in Table 1.

The resin chosen is tri-functioned epoxy resin TDE - 85\# from jindong chemical plant, its properties are listed in the following Table 2 .

Table 1. Basic Characteristics of T700S - 12K

\begin{tabular}{|c|c|c|c|}
\hline Type & $\begin{array}{c}\text { T700S- } \\
\mathbf{1 2 K}\end{array}$ & $\begin{array}{c}\text { Fiber density } \\
(\mathbf{g} / \mathbf{c m 3})\end{array}$ & $\begin{array}{c}\mathbf{1 . 7 4} \mathbf{1 . 7 9} \\
\mathbf{g} / \mathbf{c m 3}\end{array}$ \\
\hline \hline $\begin{array}{c}\text { monofilament } \\
\text { diameter }\end{array}$ & $8 \mu$ & Elongation $(\%)$ & $\geq 1.5$ \\
\hline tensile strength $(\mathrm{GPa})$ & 4.827 & Carbon content & $\geq 95 \%$ \\
\hline elastic modulus $(\mathrm{GPa})$ & 210 & & \\
\hline
\end{tabular}

Table 2. Performance Parameters of Epoxy Resin TDE - 85\#

\begin{tabular}{|c|c|c|}
\hline \multirow{12}{*}{$\begin{array}{l}\text { Properties of the } \\
\text { curing }\end{array}$} & Impact strength $\mathrm{Kg}-\mathrm{cm} / \mathrm{cm} 2$ & 13.9 \\
\hline & Bending strength $\mathrm{Kg} / \mathrm{cm} 2$ & 1690 \\
\hline & Compressing strength $\mathrm{Kg} / \mathrm{cm} 2$ & 1636 \\
\hline & Brinell hardness $\mathrm{Kg} / \mathrm{cm} 2$ & 1807 \\
\hline & Tensile strength $\mathrm{Kg} / \mathrm{cm} 2$ & 638 \\
\hline & Elongation \% & 2.1 \\
\hline & Shear strength(RT) & 142 \\
\hline & Sueface resistance $\Omega$ & $1.7 \times 10^{\wedge} 14$ \\
\hline & Volume resistance $\Omega \mathrm{cm}$ & $3.4 \times 10^{\wedge} 16$ \\
\hline & Dielectric constant $\zeta$ & 3.7 \\
\hline & Dielectric loss $\operatorname{tg} \delta$ & $2.2 \times 10^{\wedge}-2$ \\
\hline & $\begin{array}{l}\text { Breakdown voltage strength } \\
\qquad \mathrm{KV} / \mathrm{mm}\end{array}$ & 23.3 \\
\hline
\end{tabular}

\section{PHYSICAL DIMENSION OF THE FLANGE}

According to the requirements of the connection size of the truss structure, the internal diameter of the flange cylinder is $45 \mathrm{~mm}$, and the external diameter is $51 \mathrm{~mm}$; the external diameter of the flange disc is $90 \mathrm{~mm}$, and the thickness is $3 \mathrm{~mm}$. According to the requirements of bonding strength, the length of the flange cylinder is $90 \mathrm{~mm}$, and there is a round transition with a radius of $10 \mathrm{~mm}$ between the flange disc and the flange cylinder, to decrease the stress concentration. The shape and size of the flange is shown in Fig. (3). 


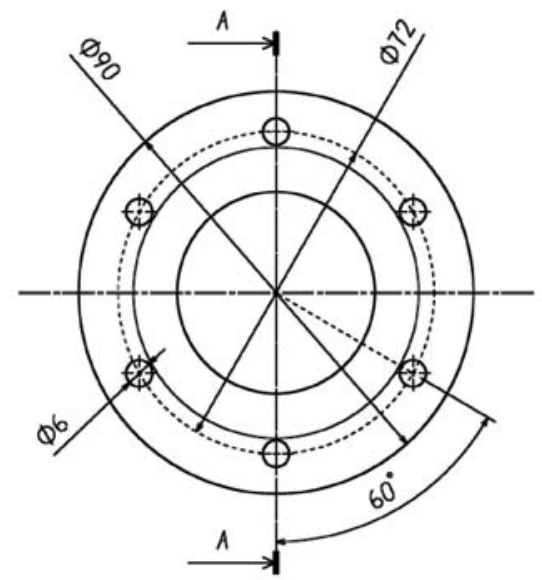

Fig. (3). Physical dimension of the flange.

Since the mechanical properties of the composite material are greatly impacted by processing parameters, and theories on design criteria of the mechanical properties of three-dimensional braiding composite material are not yet completed, the one dimension quantity method is adopted to carry out the research. The volume content of the fiber is set as $50 \%( \pm 2 \%)$, the braiding angle of the flange as $20^{\circ}$, and the pitch length as $5 \mathrm{~mm}$, the braiding is completed by Beijing Boruiding Science and Technology Co. Ltd. under set-up parameters adopting three-dimensional full fivedirections braiding technology. The flange preform is shown in Fig. (4). After braiding by the weaving technology, the preform units are cut and separated one by one. Because of the cutting, the flange neck and the edges of the flange disk are provided with burr, and the braiding parameters can not be guaranteed, such that after curing, this region can not reach the requirements of the designed properties. But in view of the process, the loosening at the edges can not be avoided. Therefore, it is only necessary to make the braiding size of the preform lager than the physical dimension of the part, and cut off the related region after curing.

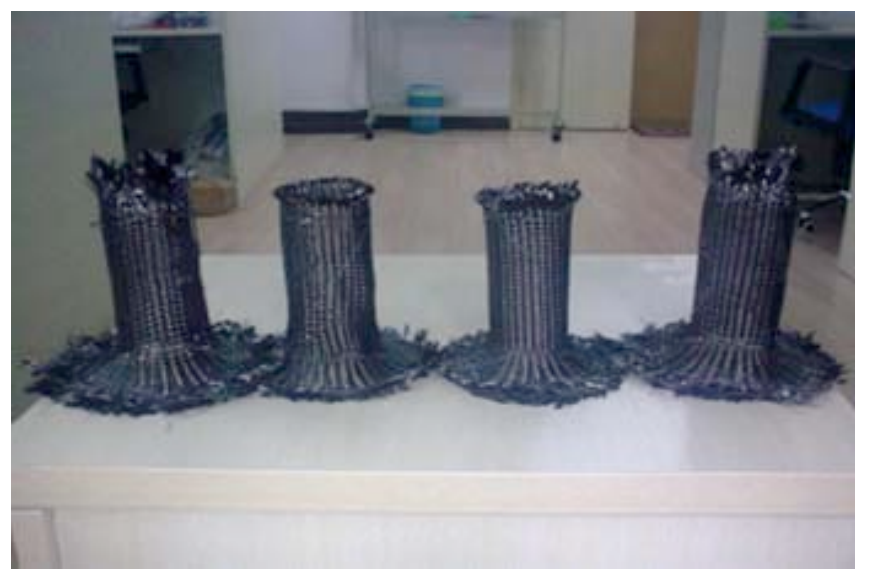

Fig. (4). Manufacture of the flange preform.

\section{THE FORMING PROCESS OF THE FLANGE}

The RTM process is adopted to form the flange, it mainly includes steps of the manufacture of the RTM process mold, injection, curing and release of the resin.

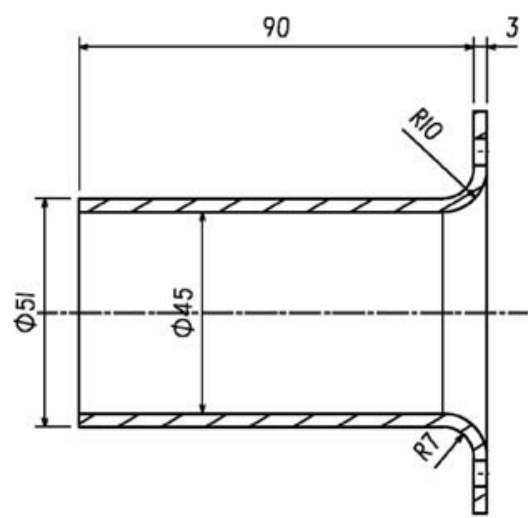

\subsection{Designing of the Mold}

The designing of the mold is one of the key steps of the RTM forming process. The quality of the mold not only decides the inherent quality of the composite material, but also decides the surface grade of the composite material. As the property of the composite material is greatly impacted by the composite process, the dispersibility of the properties of the product is frequently large. Therefore, designing an appropriate mold can insure that the dispersibility of the properties of the cured composite material is relatively smaller.

The height of the projection of the male mold is slightly higher than the flange neck, and the higher part is the area for the main passage and bypass passage. The end face of the projection of the male mold is in connection with the end face of the intra-cavity of the female mold. The resin is injected from the pores at the end face and flew from the four pores at the side surface to the braiding uniformly. The design figure of the mold is shown as Fig. (5). The male mold and the female mold is shown as Fig. (6).

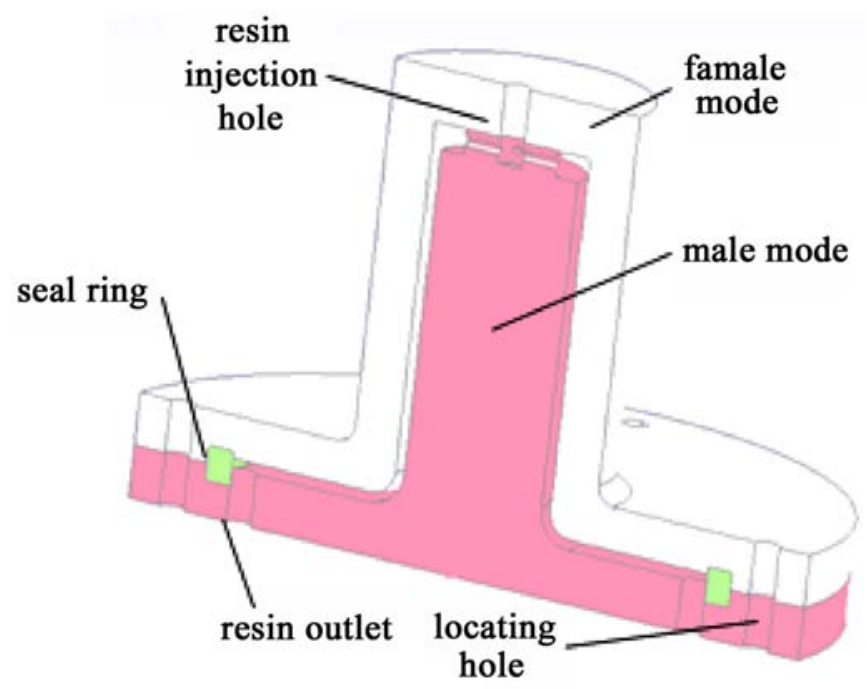

Fig. (5). Half sectional view of the mold. 


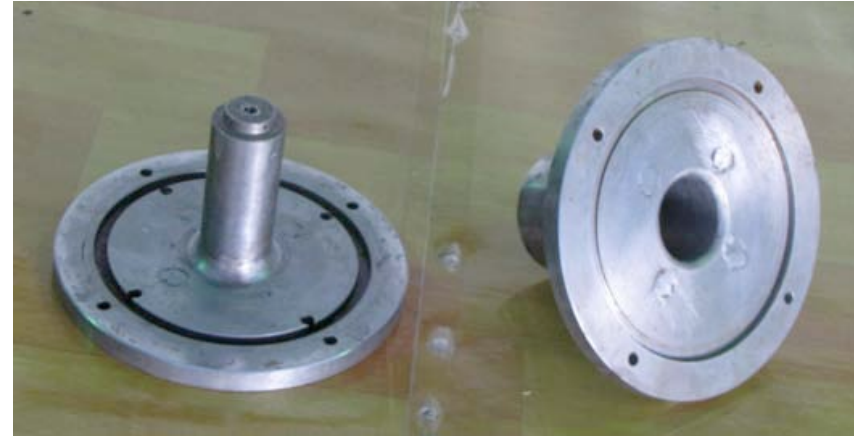

Fig. (6). Photos of the male mold and the female mold.

\subsection{Forming}

In the three-dimensional braided carbon-fiber composite flange, the base material is TDE - 85\# epoxy resin, and the reinforcement material is carbon fiber. Also, 70\# anhydride is chosen as the curing agent, and aniline is chosen as the accelerant. Upon curing, the resin, curing agent and the accelerant is mixed in the ratio of 100:113.7:0.1, and the curing is carried out at an injection pressure of $0.3 \mathrm{mpa}$ and at $85{ }^{\circ} \mathrm{C}$ for one hour, then raised to $120{ }^{\circ} \mathrm{C}$ for another one hour, followed by natural cooling and releasing. The flange joint is shown as Fig. (7).

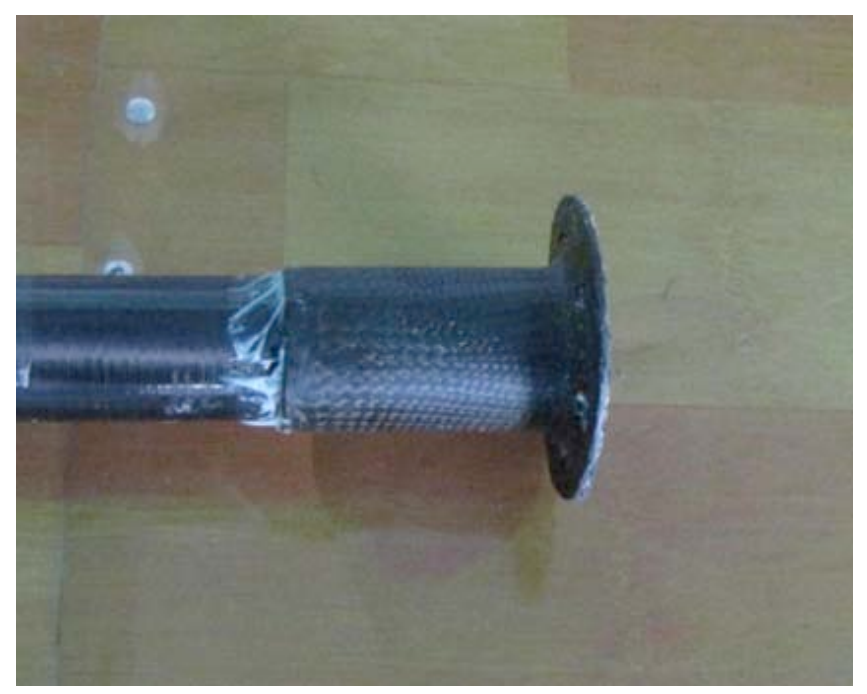

Fig. (7). Advanced composite material flange.

\section{TESTS}

Through the tensile and bending tests of advanced composite material flange, the mechanical properties of which is obtained, and in conjunction with the tensile and bending tests of aviation aluminum alloy flange, the mechanical properties of both are compared. In the tests, the physical dimensions and the test methods of the aviation aluminum alloy flange are in accordance with those of the advanced composite material flange.

\subsection{Tensile Tests of Advanced Composite Material Flange}

A tensile test is carried out to the flange joint to test its tensile property. Currently, there are no test criteria as reference on the mechanical properties of composite material flange joints. The present paper designed the above mentioned experiment according to the operating requirements of the flange. The loading rate of the testing machine is $0.5 \mathrm{~mm}$ / min, and the loading mode for tensile test of the flange joint is shown as the Fig. (8).

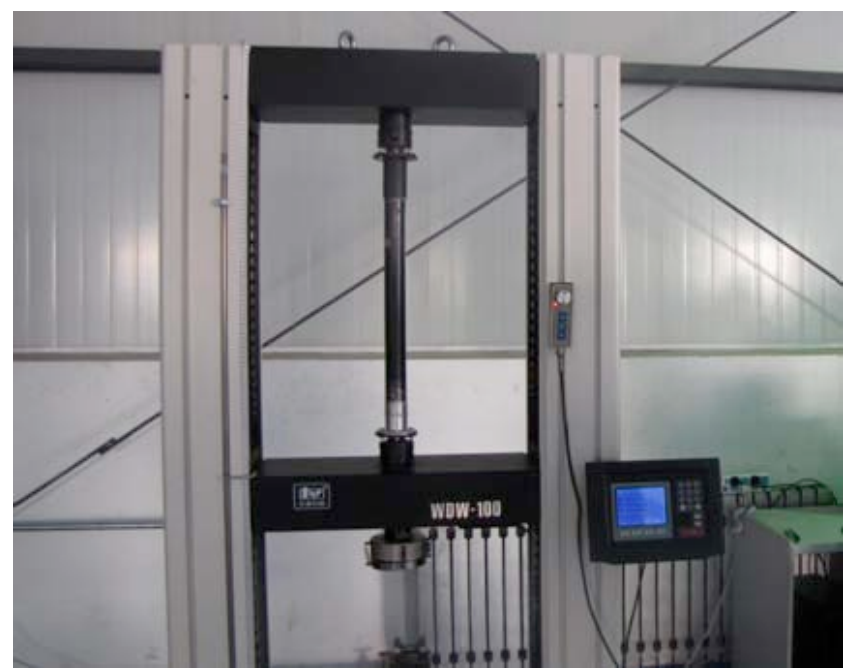

Fig. (8). Composite material flange tensile test.

As observed by the test, when the experimental load reached $20000 \mathrm{~N}$, the specimen started to make a cracking sound. As the load continued, the bolt holes for connecting of the flange started to deform, after which, a crack was first seen at the round corner which connects the flange disc and the flange cylinder. At last, the whole round corner of the flange neck and the flange disc were seriously deformed, and the flange neck was completely broken. The whole destructed flange is shown as Fig. (9).

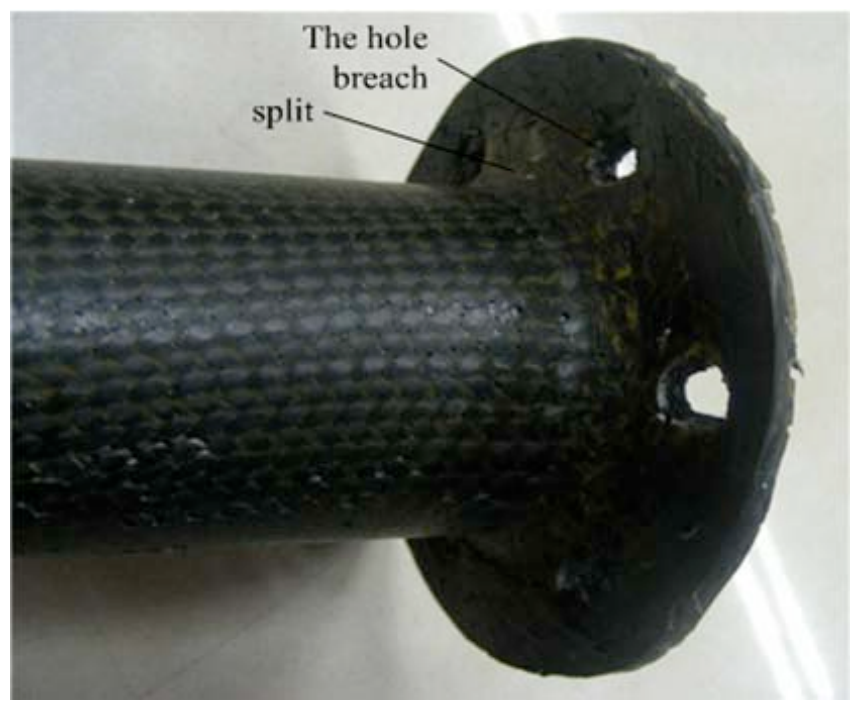

Fig. (9). Destroy of the composite material flange by the tensile test.

The load - displacement curve of the flange by the tensile test is shown as Fig. (10). It can be recognized in the curve that the whole test curve of the flange is changed as a line. The load is decreased rapidly after reaching a maximum of $29321 \mathrm{~N}$, and the test is finished after the load is decreased to $24000 \mathrm{~N}$, by then the flange is completely damaged. 


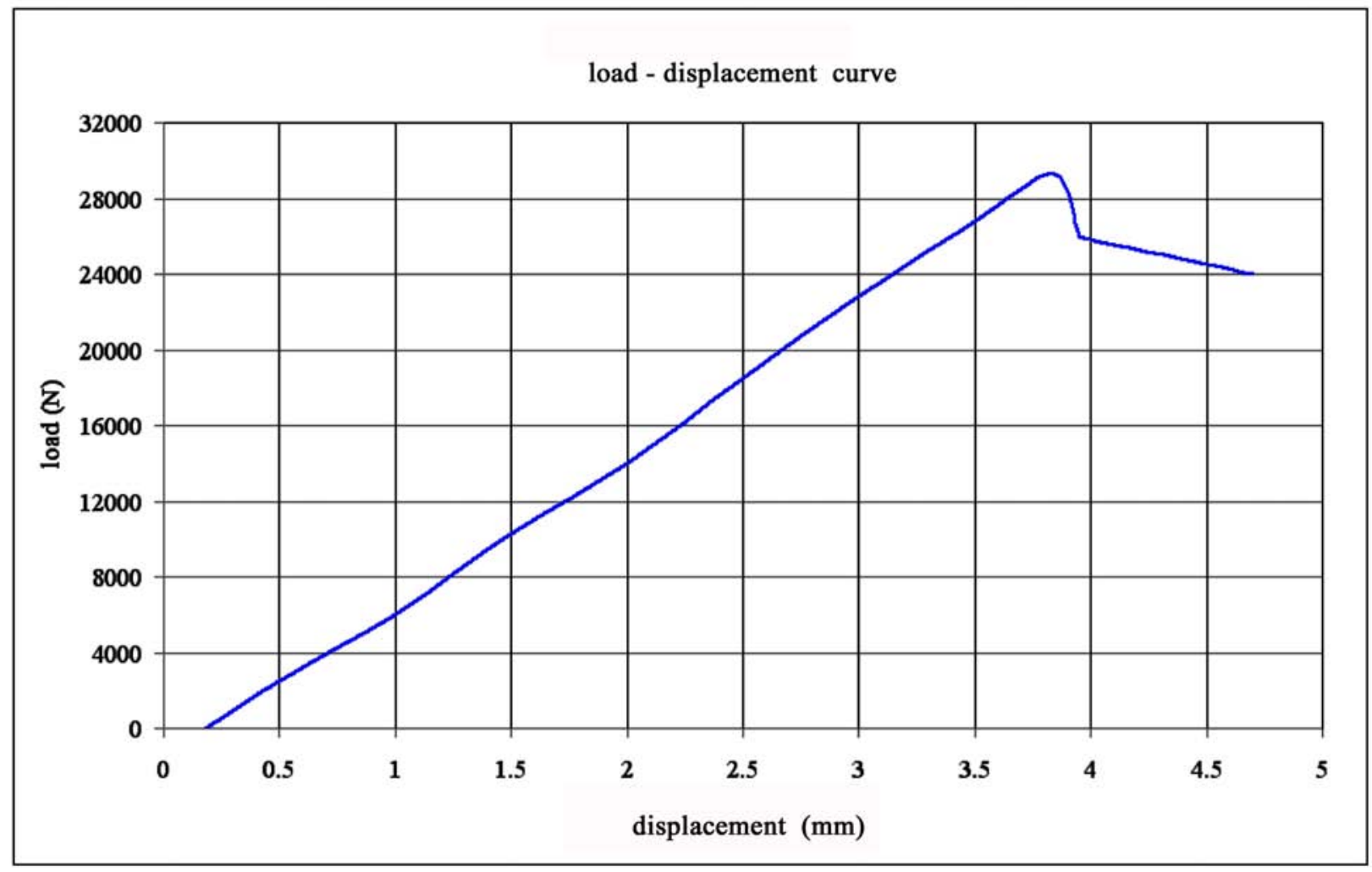

Fig. (10). Load - displacement curve of the composite material flange by the tensile test.

\subsection{Bending Tests of Advanced Composite Material Flange}

A bending test is carried out to an advanced composite material flange joint, to measure its bending property. Considering the use and the stress conditions of the flange joint on the aerostat truss structure, the present paper designed an experiment program: the distance between the bearings of both sides of the specimen is $520 \mathrm{~mm}$, the distance from the loading head to the bearing is $260 \mathrm{~mm}$, and the loading rate of the test machine is $0.5 \mathrm{~mm} / \mathrm{min}$. The bending test of the flange joint is shown in Fig. (11).

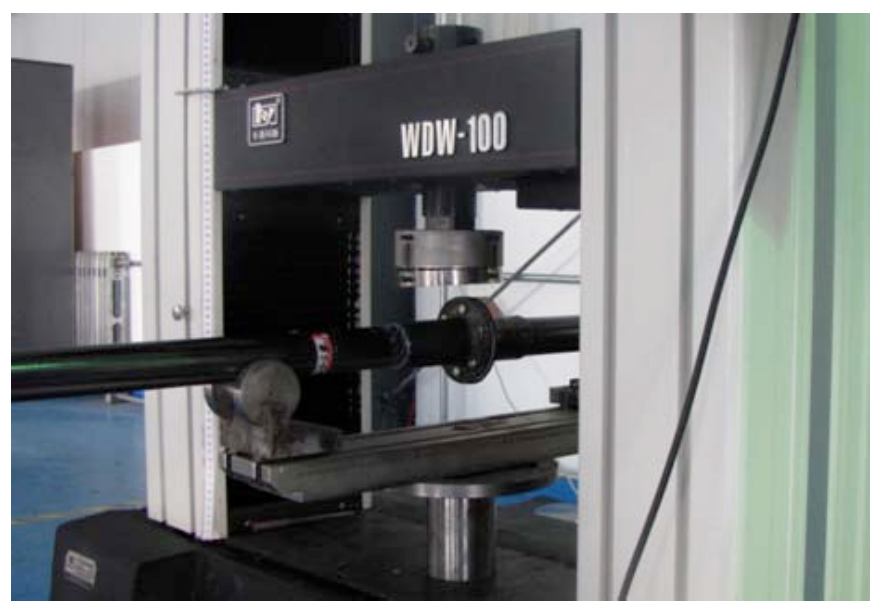

Fig. (11). Composite material flange bending test.

As observed by the test, when the experimental load reached $3620 \mathrm{~N}$, the specimen started to make a cracking sound. As the load continued, the sound did not stop, and the connecting bolt holes at the down side of the flange started to deform, after which, a crack condition appeared at the transition round corner near the bolt holes. Along with the increasing of the load, the crack enlarged and extended along both sides. At last, the flange disc was seriously deformed. The destructed form of the whole flange by the test is shown as Fig. (12).

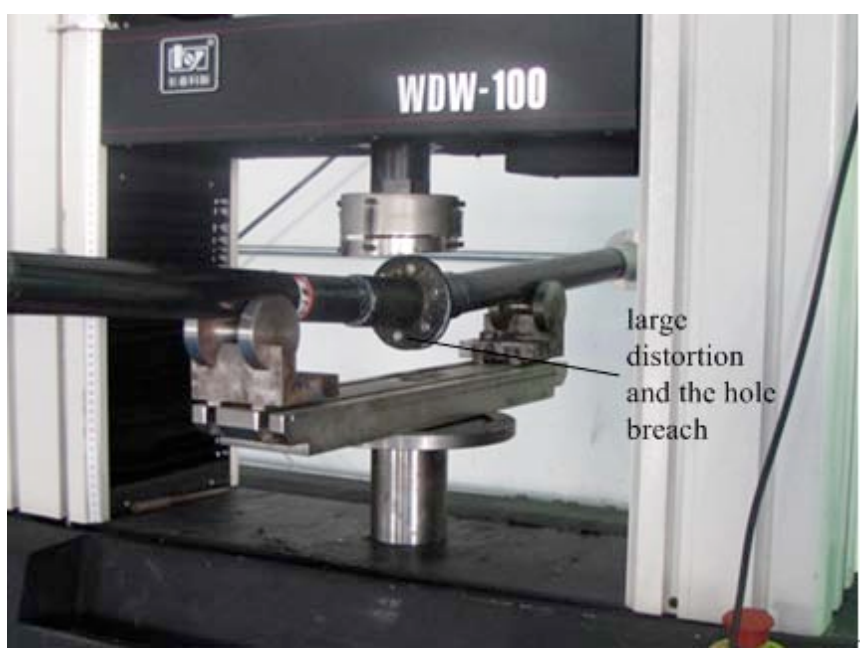

Fig. (12). Destroy of the composite material flange by the bending test.

The load - displacement curve of the flange bending test is shown as Fig. (13). From the load curve, it can be seen that the whole test curve of the flange is basically changed in line. The slope of the curve is slightly decreased when the load reaches $4000 \mathrm{~N}$. After the maximum of $5110 \mathrm{~N}$, the load rapidly drops, and when the load draps to $3800 \mathrm{~N}$, the test is stopped, by then the flange is completely damaged. 


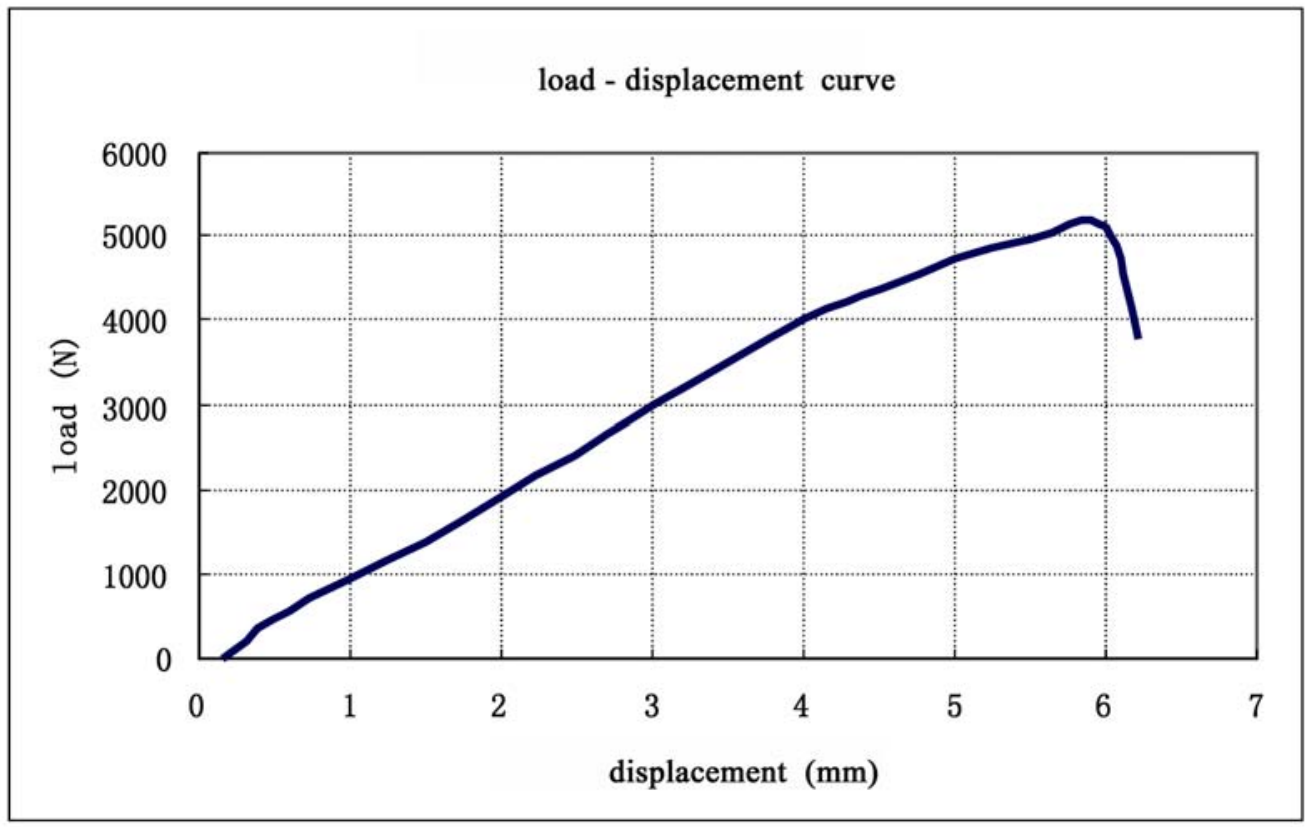

Fig. (13). Load - displacement curve of the composite material flange by the bending test.

\subsection{Tensile Tests of the Aviation Aluminum Alloy Flange}

Referring to the tensile test method of advanced composite material flange, the tensile test of aviation aluminum alloy flange is carried out. The flange is fixed with the test machine by adhesively bonding carbon fibre pipes. The loading rate of the test machine is $0.5 \mathrm{~mm} / \mathrm{min}$. The loading test is shown as Fig. (14). When the load reaches $30000 \mathrm{~N}$, the flange begins to deform, and when reaching $40000 \mathrm{~N}$, the bolt holes crack and the flange is destroyed. The destroyed flange is shown as Fig. (15).
The load - displacement curve of the tensile test of a typical metal flange is shown as Fig. (16). The whole load curve is basically changed in line. The flange reaches its maximum tensile load at $40000 \mathrm{~N}$.

\subsection{Bending Tests of the Aviation Aluminum Alloy Flange}

Referring to the bending test method of advanced composite material flange, the bending test of aviation aluminum alloy flange is carried out. The flange is fixed

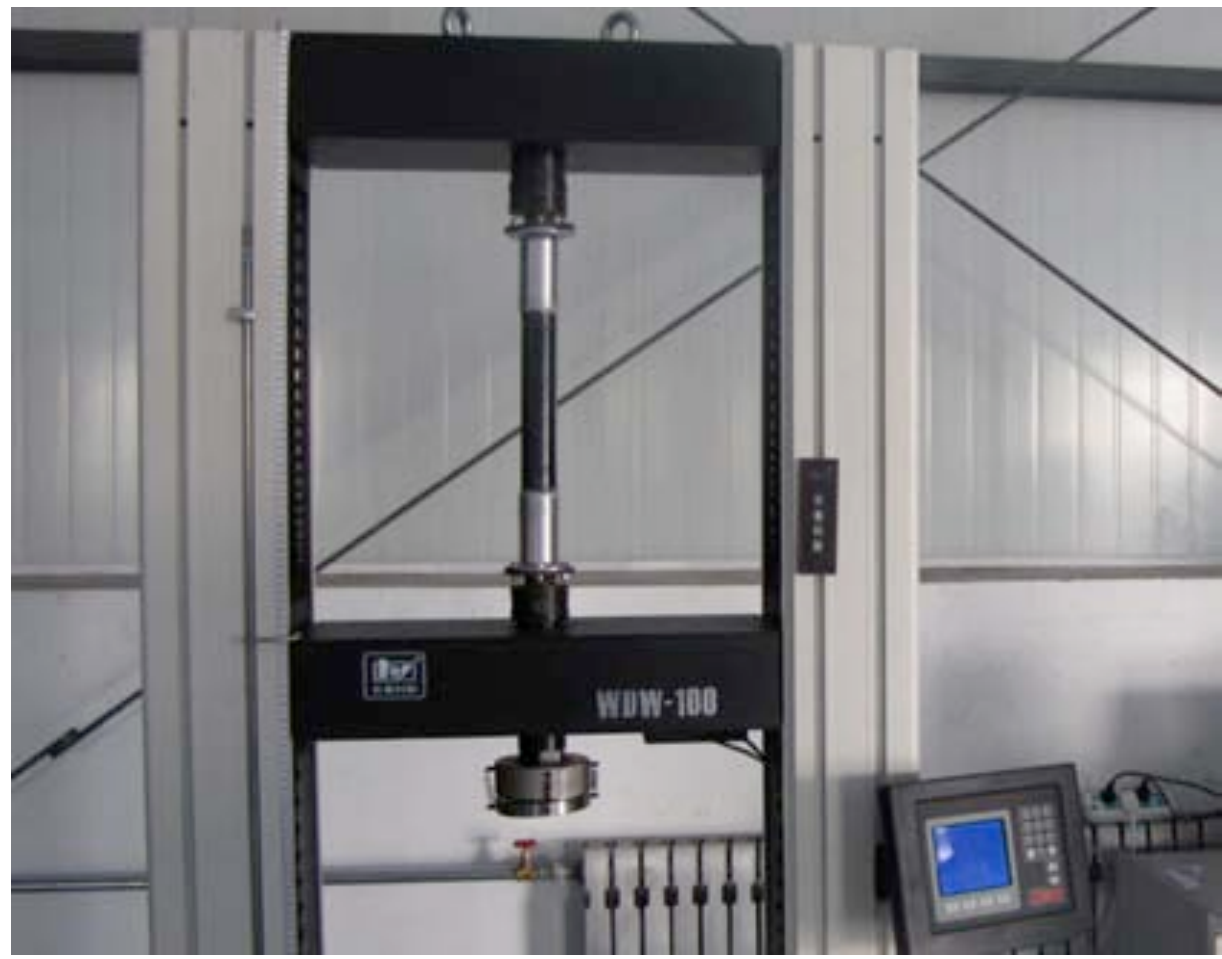

Fig. (14). Aviation aluminum alloy flange tensile test. 


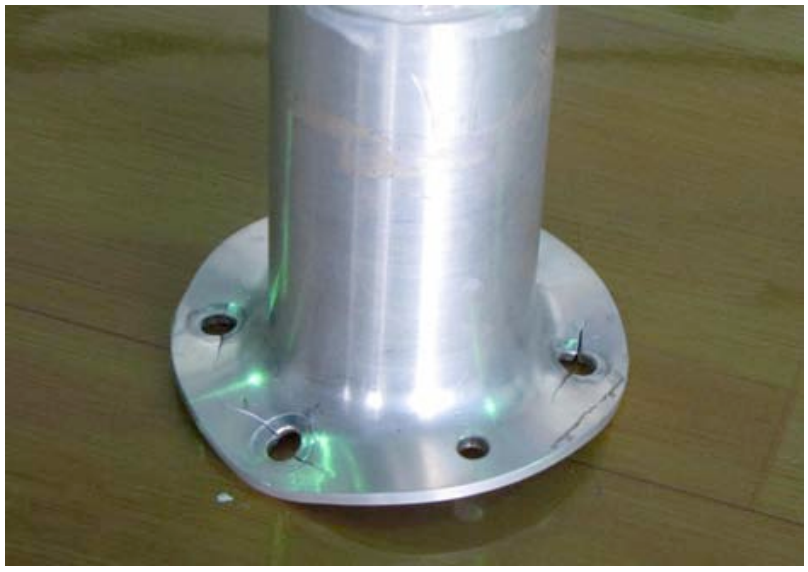

Fig. (15). Destroy of the aviation aluminum alloy flange by the tensile test.

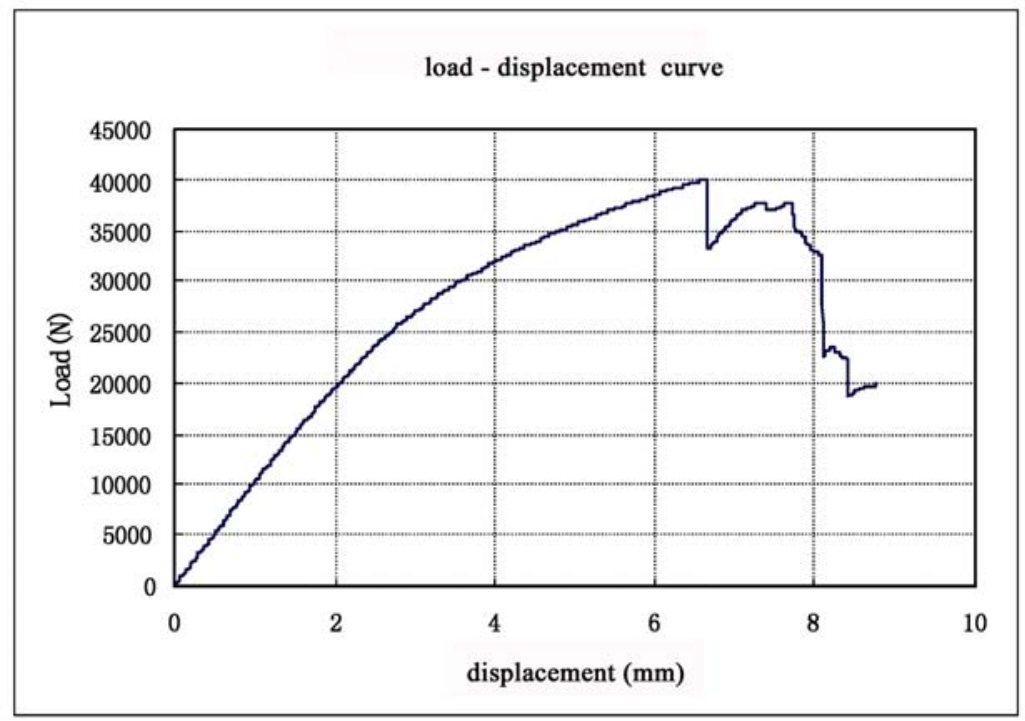

Fig. (16). Load - displacement curve of the aviation aluminum alloy flange by the tensile test.

with the bearing by adhesively bonding carbon fibre pipes. The distance between two bearings is $520 \mathrm{~mm}$, the distance from the bearing to the center loading point is $260 \mathrm{~mm}$, and the loading rate of the test machine is $0.5 \mathrm{~mm} / \mathrm{min}$. The bending test is shown as Fig. (17). When the load reaches $4500 \mathrm{~N}$, the flange begins to deform, and when reaching

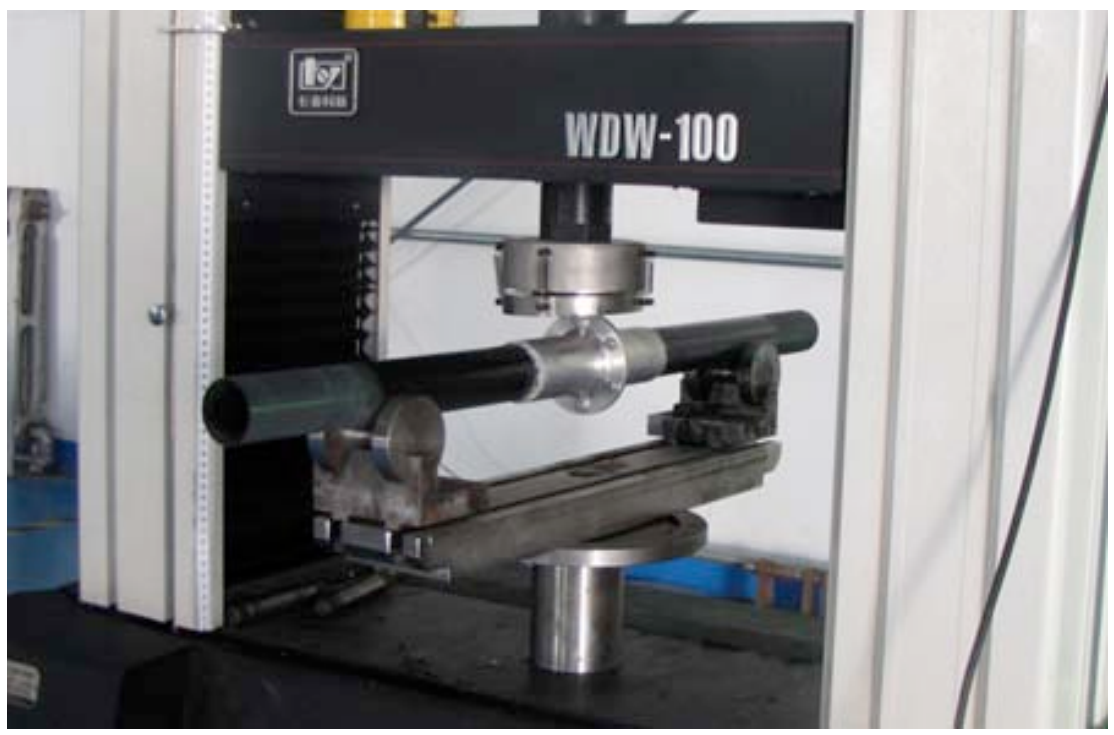

Fig. (17). Aviation aluminum alloy flange bending test. 


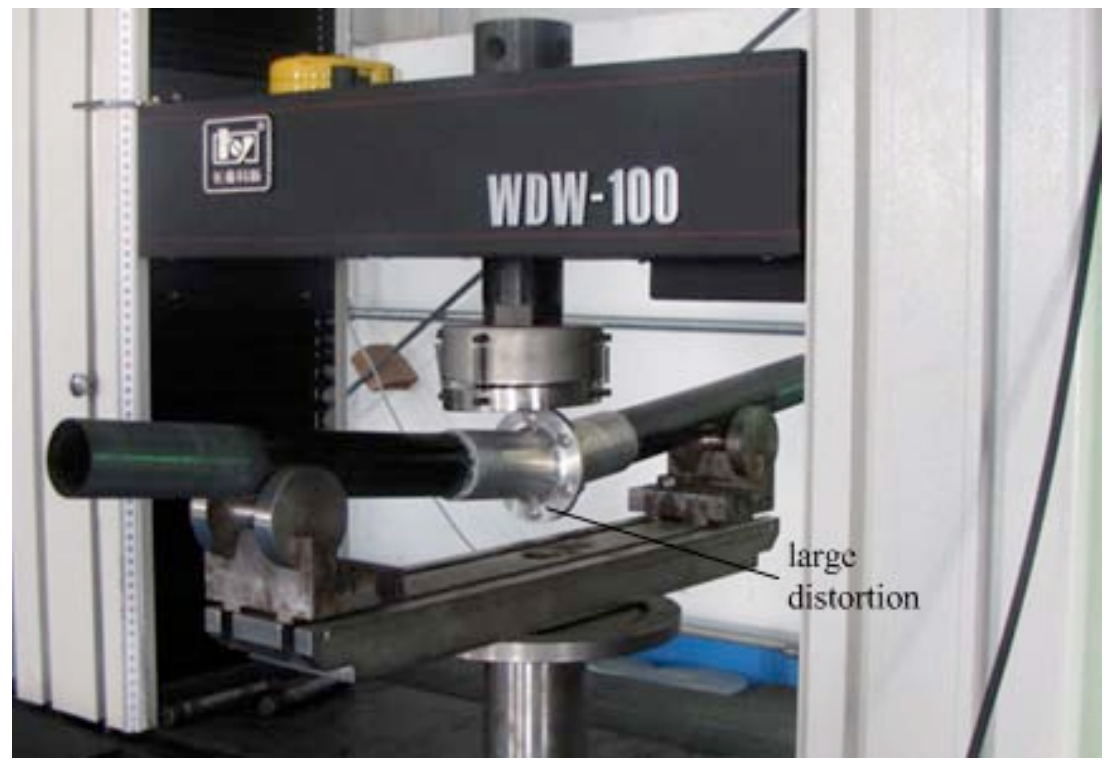

Fig. (18). Deform of the aviation aluminum alloy flange by the bending test.

$6150 \mathrm{~N}$, a bigger deform appears at the bottom of the flange, by then the test is stopped. The deform condition is shown as Fig. (18).

The load - displacement curve of the tensile test of a typical metal flange is shown as Fig. (19). The whole load curve is basically changed in line, although the load vibrates in small amplitude after $5800 \mathrm{~N}$. When the load reaches its maximum of $6150 \mathrm{~N}$, the flange is largely deformed and the test is stopped.

\subsection{Summary of the Tests}

As is known from the tensile and bending tests of the advanced composite material flange and the aviation aluminum alloy flange, under the condition of same physical dimension, the tensile and bending properties of the advanced composite material flange are slightly lower than those of the aviation aluminum alloy flange. However, the weight of the former is $57 \%$ of the latter, thus under the condition of same weight, the tensile property of the advanced composite material flange is 1.28 times of that of the metal flange, and the bending property 1.45 times. The equivalent mechanical properties of the former are apparently better than those of the latter.

\section{FINITE ELEMENT ANALYSIS}

Since the radius of the circular arc of the flange disc at the concentration of stress on the advanced composite material flange joint is relatively small, the desired distribution of strain and stress can not be directly measured. Thus, through simulations of finite element analysis, the limiting loads in the above tests are adopted to analyze the stress distribution of the whole flange, to derive the breaking strength. Since currently there are not yet calculation methods for mechanical properties of three-dimensional full five-directional

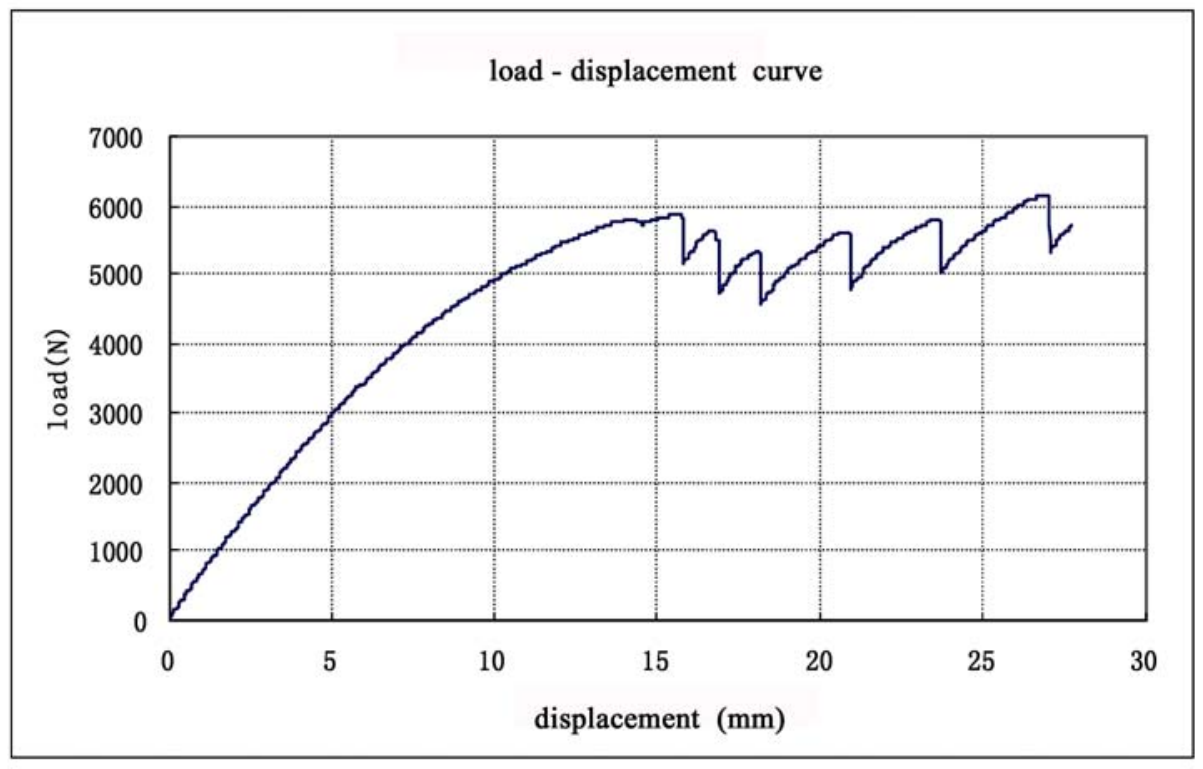

Fig. (19). Load - displacement curve of the aviation aluminum alloy flange by the bending test. 


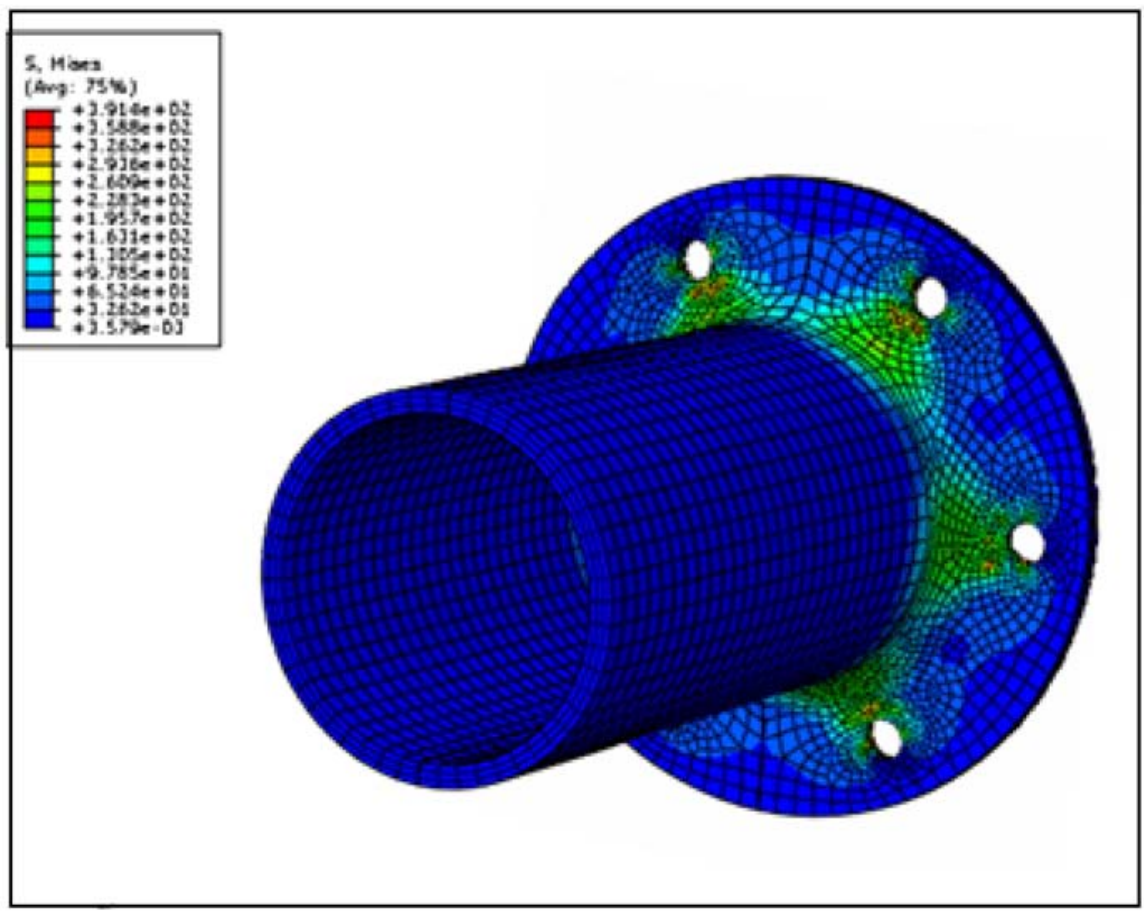

Fig. (20). Stress nephogram of flagne by the tensile test.

advanced composite material flange, the present paper adopts the calculation methods for isotropy homogeneous materials to proceed the model analysis, and carry out the demonstrations in conjuntion with the test results. The tensile modulus of the material is $106 \mathrm{GPa}$, and the Poisson ratio is 0.3 [8]. The loads of the tensile and bending finite element analysis are the breaking loads in the tests. The flange model is analyzed as linear elasticity.

As is obtained from the finite element analysis, the maximum stress of the advanced composite material flange under the function of the breaking load of the tensile test is
$391 \mathrm{mpa}$, and locates at the flange hole and the round corner. The stress distribution of the flange under stress is shown as Fig. (20), which is in good agreement with the destroy condition of the tensile tests. In the finite element analysis of the bending tests, for the convenience of loading, the flange and the adhesively bonded carbon fibre pipes are considered as a whole to build the model. Since the root of the flange is the area with the biggest load, the analysis precision is not affected. The stress analysis is shown as Fig. (21). The maximum stress of the flange is $366 \mathrm{mpa}$, and locates at the flange holes and the round corners near the flange holes, which is in good agreement with the test results.

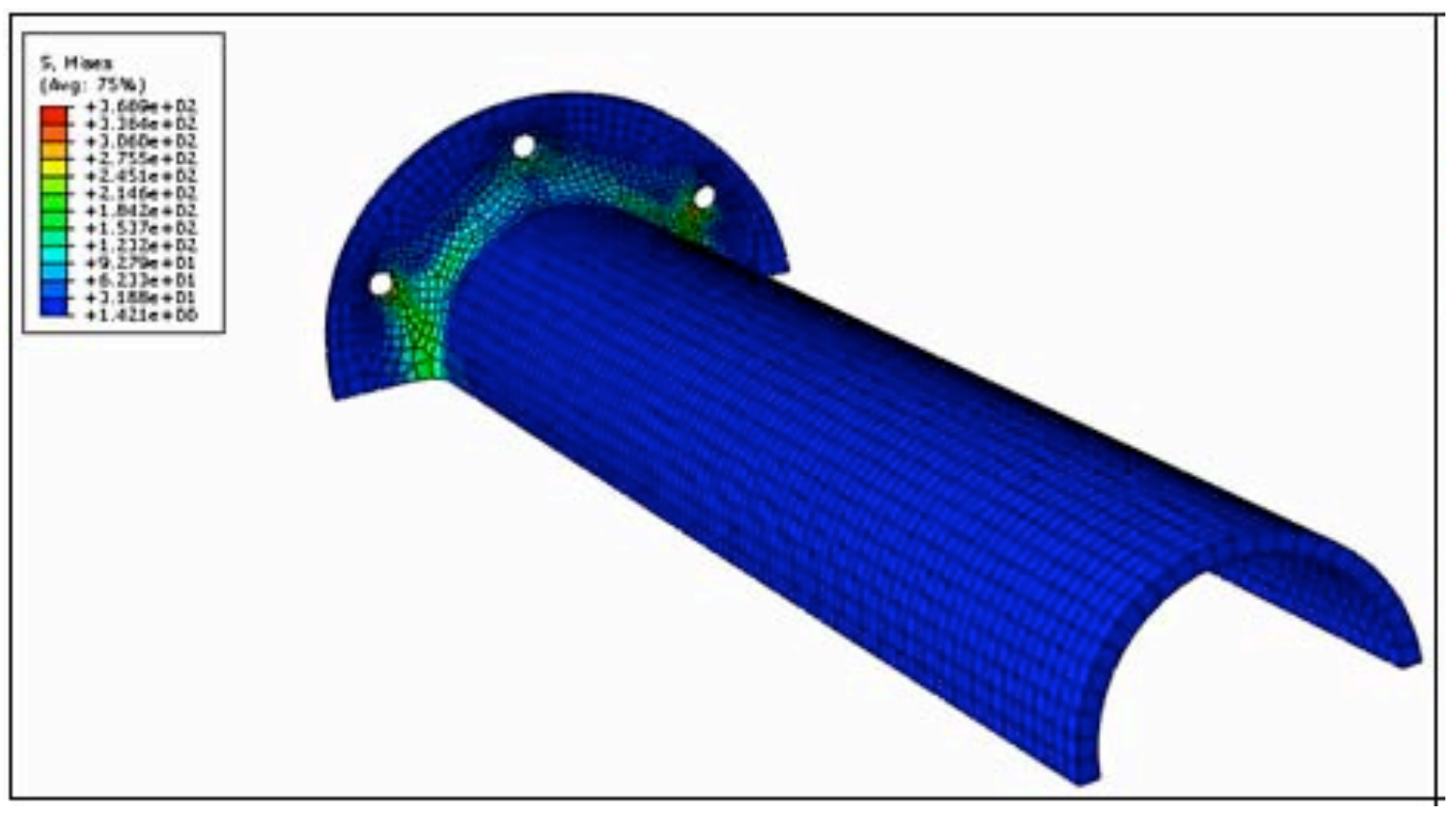

Fig. (21). Displacement nephogram of flange by the bending test. 
From the stress and strain distribution resulted from the finite element analysis, it is known that the round corner joints and the flange holes of the flange are the weakness, which have to be strengthened, and the stress of the flange cylinder is relatively smaller, which can be properly weakened.

\section{CONCLUSION}

The present flange is manufactured by a weaving preform and the RTM forming process. The manufacturing process is feasible and the processing efficiency is high. By this process, three-dimensional braided composite material joint can be manufactured in mass production.

The carbon fiber braided composite material joint in concern with the present paper is better than aviation aluminum alloy joint under the condition of the same quality, which suggests that the carbon-fiber composite flange joint researched in the present paper has obvious advantages in substituting aluminum alloy joint in the manufacturing of the truss structures for stratosphere aerostats.

The use of advanced composite material flange connecting pieces has solved the problems of electrical erosion and thermal stress which existed in carbon fibre composite truss structure when using traditional metal connecting pieces.
In conjunction with the results of the finite element analysis, mechanical properties can be further enhanced by the improvements of the braiding process, the forming process and the physical dimension.

\section{REFERENCES}

[1] R. M. Crane, and A. B. Macander, "Mutidimensionally braided fiber reinforced composite material characterization", Naval Engineers Journal, vol. 96, No. 6, pp. 52-560, 1984.

[2] L. Jialu, "Three dimensional braiding composites for structural components", Journal of Spacecraft Recovery \& Remote Sensing, vol. 28, No. 2, pp. 53-58, 2007. [in Chinese].

[3] E. D. Reese, A. P. Majidi, and R. B. Pipes, "Friction and wear behavior of fiber FP/aluminum composites", Journal of Reinforced Plastics and Composites, vol. 7, No. 11, pp. 500-514, 1988.

[4] R. A. Florentine, "Characterization of 3D braided compositesstatus of structure-property design data for magnaweave-reinforced carbon-epoxy aircraft composites", SAMPE, pp. 433-443, 1989.

[5] L. W. Gause, and J. Alper, "Structural properties of braided graphite/epoxy composites", ASTM Journal of Composites Technology Research, vol. 9(4), pp. 141-150, 1987.

[6] S. Huiyu, "RTM process and mechanical properties of 3D braided composite materials", Journal of Materials Engineering, vol. 5, pp. 34-40, 1998. [in Chinese].

[7] L. Zhenguo, "Concept of three-dimensional full five-direction braided preforms", Journal of Materials Engineering, pp. 305-308. 2008 [in Chinese].

[8] Z. Fan, "A new scheme and micro-structural model for 3D full 5directional braided composites", Chinese Journal of Aeronautics, vol. 23, No. 1, pp. 61-67, 2010.

This is an open access article licensed under the terms of the Creative Commons Attribution Non-Commercial License (http: //creativecommons.org/licenses/by$\mathrm{nc} / 3.0 /$ ), which permits unrestricted, non-commercial use, distribution and reproduction in any medium, provided the work is properly cited. 